\title{
Evaluation of the aroA mutant of Corynebacterium pseudotuberculosis in cellular and murine models
}

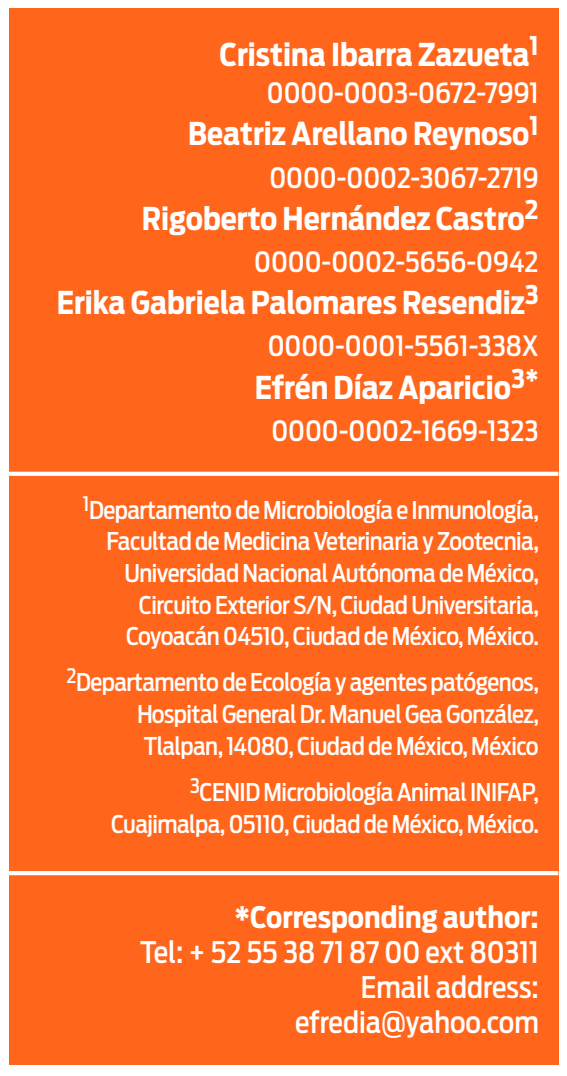

Received: 2016-04-18 Accepted: 2016-11-11

Published: 2016-12-09

Additional information and declarations can be found on page 14

@) Copyright 2016 Cristina Ibarra Zazueta et al.

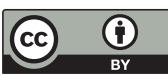

Distributed under Creative Commons CC-BY 4.0

\begin{abstract}
Caseous lymphadenitis of small ruminants causes economic losses worldwide. To date, no effective vaccine has been developed against the causative agent of this disease, Corynebacterium pseudotuberculosis. The objective of the present work was to evaluate an aroA mutant gene strain of $C$. pseudotuberculosis in cellular and murine models, for attenuation and the ability to stimulate an immune response. The intracellular survival of the aroA mutant strain and the wild type strain (WT) of C. pseudotuberculosis was evaluated in J774A. 1 murine macrophages using a multiplicity of infection (MOI) of 1:1 with the following infection times: $30 \mathrm{~min}$, and 1, 2, 4, 8, 12, and $24 \mathrm{~h}$. The largest difference in the intracellular survival of the mutant was observed 30 min post-infection. After subcutaneous skin vaccination, the subcutaneous lesion progression observed on the $14^{\text {th }}$ day was more severe in those animals that were vaccinated with the WT strain. An analysis of the residual virulence in the murine model did not reveal any bacteria in mice vaccinated with the aroA strain on day 28 post-vaccination. Mice vaccinated with the mutant showed $50 \%$ protection against the intraperitoneal challenge, exceeding that of the control group $(41.67 \%)$. We conclude that the virulence of the aroA mutant was significantly attenuated in both cellular and murine models according to the residual virulence detected in mice. However, vaccination with the mutant failed to confer at least $80 \%$ protection, which is desirable for an immunogen. Hence, this study contributes to the knowledge of the immune response against Corynebacterium pseudotuberculosis.
\end{abstract}

Keywords: Corynebacterium pseudotuberculosis, aroA gene, vaccination, cellular model, murine model.

\section{Introduction}

Corynebacterium pseudotuberculosis is a Gram-positive facultative intracellular bacterium and intracellular coccobacillus, capable of fermenting carbohydrates, producing urease, phospholipase D and catalase. Two biotypes are known of this species, a nitrate positive group infecting only horses and a nitrate negative group infecting only goats and sheep ${ }^{1}$. C. pseudotuberculosis is the causative agent of 
caseous lymphadenitis in small ruminants and typically produces abscesses with caseous necrosis in superficial lymph nodes, subcutaneous tissue, lungs, kidneys, liver, and spleen ${ }^{2}$. In infected horses, there are three clinical manifestations: subcutaneous or muscular abscess, mainly in the pectoral and abdominal regions; internal infection causing visceral abscess (liver, kidney, lungs, and spleen); and ulcerative lymphangitis, which results in limb inflammation, cellulitis and severe lameness $^{3}$. To control this disease, several bacterins and live vaccines have been applied and found to exert partial protective effects ${ }^{4}$. The use of a bacterin-toxoid prepared with the phospholipase D exotoxin increased the antibody levels against exotoxin in sheep, reducing the number and size of the lesions relative to those in non-immunized animals ${ }^{5}$. However, vaccination with this preparation did not protect the animals against experimental infection ${ }^{5}$.

The maintenance of a live strain of C. pseudotuberculosis for use as an immunogen has been attempted, but the results have not been satisfactory. One strategy that has been used to obtain attenuated strains of microorganisms is to perform several mutations in the genes affecting bacterial metabolism, such as those associated with aromatic amino acids ${ }^{6}$. In this regard, the aro genes have become a mutational target for modification and virulence attenuation of pathogenic strains of bacteria. The aro genes are involved in the shikimate biosynthetic pathway, in which 3-deoxy-D-heptulosonate-7-phosphate (DAPH) is converted to chorismate, which is required for the synthesis of aromatic amino acids that are important for bacterial metabolism. Disruption of genes associated with this pathway has been successfully used for the generation of live attenuated bacterial strains ${ }^{7}$. For example, several mutations have been achieved in the aroA gene of Salmonella enterica, subsp. enterica serovar Abortus equi, and it was observed that one major effect produced by these mutations corresponds to the inability of the bacteria to generate aromatic metabolites, such as phenylalanine, tyrosine, and tryptophan, which are essential for bacterial metabolism; thus, these mutants are incapable of intracellular replication ${ }^{6}$. Additionally, these mutations altered the regulation of the murA gene, which is involved in peptidoglycan synthesis, thereby causing several defects in the bacterial cell wall and the outer bacterial membrane and facilitating phagocytosis of the mutant ${ }^{6,8}$. In a study of the cp09 mutant of C. pseudotuberculosis, BALB/c mice were immunized and showed $50 \%$ survival after being challenged, intraperitoneally (i. p.), with a virulent strain at a dose of $1 \times 10^{4}$ colony-forming units (CFU) ${ }^{9}$.

The aroA gene mutant of Salmonella enterica, subsp. enterica serovar Abortus equi administered by the oral and intramuscular routes induced $100 \%$ protection against experimental infection of guinea pigs ${ }^{10}$. In contrast, attenuated mutant strains affecting the $a r o B$ and $a r o Q$ genes of $C$. pseudotuberculosis were used as immunogens in sheep but did not confer adequate protection against the experimental challenge ${ }^{11}$. An attenuated live vaccine is needed to stimulate an adequate cellular immune response and protect animals against Caseous lymphadenitis. Based on this rationale, we developed an aro $A$ mutant strain of $C$. pseudotuberculosis and tested its attenuation in a cellular and a murine model. Finally, we verified its ability to elicit an immune response to protect mice against a challenge with a virulent strain of $C$. pseudotuberculosis in the murine model. 


\section{Materials and methods}

The experimental procedure was performed under the approval of the Animal Care and Use Ethics Committee (SICUAE) of Facultad de Medicina Veterinaria y Zootecnia, Universidad Nacional Autónoma de México.

\section{Bacterial strains, media, and culture conditions}

The TOP'10 E. coli strain (F- mcrA $\Delta$ (mrr-hsdRMS-mcrBC) $\varphi 80 / a c Z \Delta M 15 \Delta$ lacX74 recA1 araD139 $\Delta$ (ara-leu) 7697 ga/U ga/K rpsL (StrR) endA1 nupG $\lambda$; Invitrogen, Carlsbad, CA, USA) was cultivated in Luria Bertani (LB) medium (Difco, Detroit, MI, USA) with orbital shaking at $200 \mathrm{rpm}$ for $16 \mathrm{~h}$ at $37^{\circ} \mathrm{C}$ (Barnstead/Lab-line Max 4000, USA). The wild type strain of C. pseudotuberculosis (WT) isolated from a goat and the reference strain of ATCC 43924 C. pseudotuberculosis were grown at $37{ }^{\circ} \mathrm{C}$ in tryptic soy medium (TSB, Difco) for $20 \mathrm{~h}$ or in tryptic soy agar (TSA, Difco) for $48 \mathrm{~h}$ (Barnstead/Lab-line Max 4000, USA). The aroA mutant strain of $C$. pseudotuberculosis was cultivated under the same conditions as the WT, with 50 $\mu \mathrm{g} / \mathrm{ml}$ of kanamycin or $100 \mu \mathrm{g} / \mathrm{ml}$ of ampicillin (Sigma Aldrich, St. Louis, MO, USA), added to the culture medium.

\section{Construction of the aroA mutant}

DNA extraction was performed using guanidine thiocyanate ${ }^{12}$, and aroA gene amplification was achieved using the $5^{\prime}$-CCCGCTCGACAAAACCTCCA-3' and 5'-ATAACTGTTGCGCCCCGGAGTC-3' primers designed from the genome sequence of $C$. pseudotuberculosis (NCBI-GenBank Accession No. NC014329), which amplified $2,138 \mathrm{bp}$, including the entire gene (1,413 bp) and the flanking sequences.

Polymerase chain reaction (PCR) reactions were performed in a final volume of $50 \mu \mathrm{l}$ using the following amplification conditions: one cycle of initial denaturation at $94^{\circ} \mathrm{C}$ for $5 \mathrm{~min} ; 33 \mathrm{cycles}$ at $94^{\circ} \mathrm{C}$ for $45 \mathrm{sec}, 65^{\circ} \mathrm{C}$ for $45 \mathrm{sec}$, and $72{ }^{\circ} \mathrm{C}$ for $2 \mathrm{~min}$; and a final extension cycle at $72^{\circ} \mathrm{C}$ for $10 \mathrm{~min}$. The amplification product was cloned into the PCR2.1 TOPO plasmid (Invitrogen, Ventura, CA, USA) ${ }^{13}$. The plasmid containing the amplified product was digested with the ECOR1 enzyme (Invitrogen) to verify the cloning and was denoted pIAaroA. The pIAaroA plasmid was then digested with Hpal enzyme (Fermentas, USA). Hpal is a site that is unique to the aroA gene; the 1222-bp kanamycin resistance gene was ligated at this site, generating the pIAaroA-km plasmid, which was transformed by electroporation into the WT strain of C. pseudotuberculosis ( $2.5 \mathrm{kV}, 200 \Omega, 25 \mu \mathrm{f}$, and 200 ng of plasmid) ${ }^{14}$. Transformant selection was performed based on the kanamycin resistance and ampicillin sensitivity of $C$. pseudotuberculosis. The level of chromosomal mutation was verified by PCR using the original primers; the PCR product was purified with a commercial QIAquick PCR Purification Kit (Qiagen, La Jolla, CA, USA). The nucleotide sequence in both directions was determined using Taq FS Dye Terminator Cycle Sequencing-Based on Fluorescence Sequencing and were analyzed on a DNA sequencer (Applied Biosystems 73730 DNA sequencing system). Sequences were verified with the Vector NTI program (Applied Biosystems, Foster City, California, USA) and Clone Manager software (Scientific \& Educational Software, Morrisville, North Carolina, USA). 


\section{Evaluation in the cellular model}

Prior to use the mouse model, attenuation of the mutant strain was established by comparing the aroA mutant with the virulent parental strain, and determining the time and the number of CFU surviving in infected cells. To evaluate the parenteral and mutant strain survival of C. pseudotuberculosis, the J774A.1 murine macrophage cell line was used ${ }^{15}$. Cells were maintained in Dulbecco's modified Eagle's medium (DMEM, Invitrogen) containing $10 \%$ fetal bovine serum (FBS), $1 \%$ non-essential amino acids, and 2-mM L-glutamine (DMEMc). For maintenance and infection, the cells were incubated with $5 \% \mathrm{CO}_{2}$ at $37^{\circ} \mathrm{C}$. Macrophages were cultivated in DMEM supplemented with $10 \% \mathrm{FBS}$ and 2-mM L-glutamine without antibiotics and then placed in polystyrene 24-well plates at a concentration of $5 \mathrm{x}$ $10^{5} \mathrm{cells} / \mathrm{ml}$ at $37^{\circ} \mathrm{C}$ with $5 \% \mathrm{CO}_{2}$ for $18 \mathrm{~h}$. Each experiment included two independent replications, and the infection assay was repeated three times.

Bacteria (C. pseudotuberculosis) were grown in brain-heart infusion (BHI) medium with orbital shaking at $200 \mathrm{rpm}$ and $37^{\circ} \mathrm{C}$ for $20 \mathrm{~h}$ until they reached the exponential phase. Prior to cell infection, they were diluted in DMEMc at $37^{\circ} \mathrm{C}$. Macrophages were infected at a multiplicity of infection (MOI) of 1: 1 . The cell culture plates were centrifuged at $400 \times \mathrm{xg}$ for $5 \mathrm{~min}$ and incubated for $30 \mathrm{~min}$ at $37^{\circ} \mathrm{C}$ with $5 \% \mathrm{CO}_{2}$. The end of this incubation was considered time zero of the infection. The cells were washed three times with phosphate-buffered saline (PBS), and $100-\mathrm{mg} / \mathrm{ml}$ gentamycin was added to the DMEMc solution to remove extracellular bacteria. Then, the cells were incubated for $1 \mathrm{~h}$ at $37{ }^{\circ} \mathrm{C}$ with $5 \% \mathrm{CO}_{2}$, at which point, the gentamicin concentration in the medium was decreased to $10 \mathrm{mg} / \mathrm{ml}$ for the remainder of the experiment. Intracellular bacterial survival was determined at $1,2,4,8,12$, and $24 \mathrm{~h}$ after time zero. The number of viable intracellular bacteria was measured by lysing the infected cells with $0.5 \mathrm{ml}$ of $0.1 \%$ Triton-PBS. The $\mathrm{CFU} / \mathrm{ml}$ value was then established by inoculating TSA plates, with $50 \mu \mathrm{g} / \mathrm{ml}$ kanamycin added for cells infected with the aroA mutant strain.

\section{Evaluation in the murine model}

To observe the appearance of skin lesions, establish the residual virulence of the aroA mutant strain, and evaluate in vivo mutant protection in terms of the immune response, BALB/c mice (6 to 7 weeks of age) were used. These mice were provided with food and water ad libitum.

\section{Evaluation of the lesions present at the vaccination site}

One problem associated with experimental live vaccines of $C$. pseudotuberculosis is the occurrence of lesions at the vaccination site ${ }^{9,} 16$. To demonstrate the in vivo mutant attenuation, the degree of the lesion at the vaccination site was evaluated. Five groups, each with three BALB/c mice, were used as follows: The first group was subcutaneously vaccinated in the midline of the back with the WT strain using $2 \times 10^{5} \mathrm{CFU}$ in $50 \mu \mathrm{l}$ of PBS. The second group was vaccinated with the mutant strain through the same route and using the same dosage as for the first group. The third and fourth groups were vaccinated in the footpad with $2 \times 10^{5} \mathrm{CFU}$ in $50 \mu \mathrm{l}$ of PBS, one with the WT and the other with the mutant strain. A control group was included and was injected with PBS in the footpad and midline of the back. The 
animals were monitored daily for 21 days to assess the degree of injury, abscess formation, and presence of fistula or exudate. They were euthanized on day 21 . The mice footpad and subcutaneous tissues were kept in $10 \%$ formalin for histopathological analysis ${ }^{17}$.

\section{Residual virulence of the aroA mutant strain}

Two groups, each with $27 \mathrm{BALB} / \mathrm{C}$ mice, were used as follows: Animals in the first group were vaccinated subcutaneously with the $\operatorname{aro} A$ mutant strain $(2 \mathrm{x}$ $10^{5} \mathrm{CFU} / 0.1 \mathrm{ml}$ of PBS), and in the second group (control) animals were vaccinated with wild type bacteria (WT), using the same route and the same dose as that used in the first experimental group. The animals were euthanized in groups of three on days $0,3,6,10,14,21,28,35$, and 42 post-vaccination. Mice spleen and liver tissues were obtained and macerated in $1 \mathrm{ml}$ of PBS. The homogenized organs were diluted at 1:10 in PBS for CFU counting, and then vaccinated (in triplicate) in TSA plates or $50-\mu \mathrm{g} / \mathrm{ml}$ kanamycin TSA plates, and incubated for $48 \mathrm{~h}$ at $37^{\circ} \mathrm{C}$.

\section{Evaluation of the in vivo mutant protection}

Twenty-four mice were vaccinated with aroA mutant strain at a concentration of $2 \mathrm{x}$ $10^{5} \mathrm{CFU} / \mathrm{ml}$ via subcutaneous injection in the withers region. The control group was injected with PBS. The challenge was performed on day 21 post-vaccination using the ATCC 43924 C. pseudotuberculosis strain at a concentration of $1 \mathrm{x}$ $10^{4} / 0.1 \mathrm{ml}$ in PBS, by intraperitoneal route ${ }^{9}$. The animals were monitored daily, and on day 28, they were euthanized and underwent necropsy for bacteriological studies in the liver and spleen.

\section{Evaluation of the humoral and cellular immune responses induced by the mutant}

An indirect commercially available enzyme-linked immunosorbent assay (ELISA) system (mouse monoclonal antibody isotyping reagent, Sigma-Aldrich) was used to determine the presence of immunoglobulins (Igs) of the $\operatorname{lgG} 1, \lg G 2 a, \lg G 2 b$, and IgM isotypes induced by C. pseudotuberculosis. Two groups of $40 \mathrm{BALB} / \mathrm{C}$ mice were used as follows: One group was subcutaneously immunized with the aroA mutant strain at a concentration of $2 \times 10^{5} \mathrm{CFU} / 0.1 \mathrm{ml}$, and the other group (control) was injected with PBS using the same subcutaneous route. Serum was obtained on days $0,3,5,7,9,12,14,21,28,35$, and 42 post-vaccination. A protein extract of the ATCC 43924 C. pseudotuberculosis strain was used as the antigen. For this purpose, the bacteria were grown in $\mathrm{BHI}$ medium for $24 \mathrm{~h}$ at $200 \mathrm{rpm}$. They were then sonicated for $12 \mathrm{~min}$ at $60 \mathrm{~Hz}$, and the obtained mass was centrifuged at $960 \times \mathrm{x}$ for $10 \mathrm{~min}$. The material was diluted to a concentration of $4 \mu \mathrm{g} / \mathrm{ml}$, as quantified by the Bradford technique, diluted again in $0.1-\mathrm{M}$ sodium bicarbonate-carbonate solution ( $\mathrm{pH}$ 9.6), and incubated for $24 \mathrm{~h}$ at $37{ }^{\circ} \mathrm{C}$ in 24well polystyrene plates. Finally, the samples were washed three times with PBS-T (PBS 1X, pH 7.4, $0.05 \%$ Tween 20). A solution of $1 \%$ skim milk was used to block the wells, and the plates were incubated for $1 \mathrm{~h}$ at $37^{\circ} \mathrm{C}$. The varied serum 
samples were diluted 1:200 in PBS and added to the plates in duplicate ${ }^{18}$. The plates were subsequently incubated for $1 \mathrm{~h}$ at $37{ }^{\circ} \mathrm{C}$ and washed three times with PBS-T. Then, $100 \mu$ of the corresponding isotype (anti-lgG 1, anti-lgG2a, anti-lgG2b, or anti-IgM) was added and diluted to 1:1,000 in PBS. The plates were incubated at room temperature for 30 min and washed three times with PBS-T. Peroxidase-conjugated Anti-IgG (obtained from a goat) was used as the secondary antibody (Sigma-Aldrich) at a concentration of 1:5,000 in PBS-T. The plates were washed with PBS-T, and 5-aminosalicylic acid was added at a concentration of $1 \mathrm{mg} / \mathrm{ml}$. Then, the plates were incubated for $15 \mathrm{~min}$ at room temperature, and $50 \mu \mathrm{l}$ of stopping solution (3-N NaOH) was added. Finally, the plates were examined at a wavelength of $490 \mathrm{~nm}$.

To determine the cytokine production induced by the aroA mutant, we tested and compared two groups of $40 \mathrm{BALB} / \mathrm{c}$ mice. On day 0 , one group was subcutaneously vaccinated with $2 \times 10^{5} \mathrm{CFU} / 0.1 \mathrm{ml}$ of the aroA mutant strain; and the control group was vaccinated with PBS. Mice were sacrificed in groups of four on days $0,3,5,7,9,12,14$, and $21^{11}$. The mice spleens were obtained under sterile conditions and washed three times with Hank's balanced salt solution, and placed in a Petri dish containing $5 \mathrm{ml}$ of DMEM (Gibco, Invitrogen, USA) with $100 \mathrm{IU} / \mathrm{ml}$ penicillin and $100 \mu \mathrm{g} / \mathrm{ml}$ streptomycin. The spleens were wrapped in sterile gauze pads to retain the tissue debris and macerated, and the cell suspension was transferred into a conical $15 \mathrm{ml}$ plastic tube containing $5 \mathrm{ml}$ of the same cell culture medium. They were then centrifuged at $400 \times \mathrm{G}$ for $3 \mathrm{~min}$. To lyse the erythrocytes, the pellet was re-suspended in $1 \mathrm{ml}$ of $0.17 \mathrm{M}$ ammonium chloride per spleen for 5 min at $4{ }^{\circ} \mathrm{C}$. Three more washes with DMEM supplemented with $10 \%$ FBS, 2 mM L-glutamine, and 0.1 mM non-essential amino acids (Gibco) were performed ${ }^{19}$. Subsequently, $5 \times 10^{6}$ lymphocyte cells were extracted from the mutant-vaccinated and control mice spleens and placed in 24-well polystyrene plates. To each well, $50 \mu \mathrm{g}$ of a protein extract of the ATCC 43924 reference strain of $C$. pseudotuberculosis diluted in PBS was added. The cells were then cultivated until the log phase for $24 \mathrm{~h}$ in BHI medium. Then, they were centrifuged, washed three times with PBS, and finally, sonicated for $12 \mathrm{~min}$ at $60 \mathrm{~Hz}^{18}$. The protein concentration was determined using the Bradford method and adjusted as required.

A positive control containing $10 \mu \mathrm{g} / \mathrm{ml}$ pokeweed (Invitrogen) and a negative control consisting of DMEM (Gibco) were used to compare to the experimental group. The plates were incubated at $37^{\circ} \mathrm{C}$ with $5 \% \mathrm{CO}_{2}$; and the supernatant was collected $24 \mathrm{~h}$ after vaccination and frozen at $-20^{\circ} \mathrm{C}$ until use. Commercial cytokine detection systems for mouse IFN- $y$, TNF- $a$, IL-4, and IL-10 were used following the manufacturer's instructions (Duoset ELISA; R\&D Systems, Minneapolis, MN, USA).

\section{Statistical analysis}

General mixed models of repeated observations were used to evaluate the aro $A$ mutant experiments in the cellular model, residual virulence in the liver and spleen, and the immune response ${ }^{20}$. For the protection experiment, the survival rates of the vaccinated and control groups were compared after the challenge. Statistical significance was considered at $\mathrm{P}<0.05$, and analyses were performed using SAS software. 


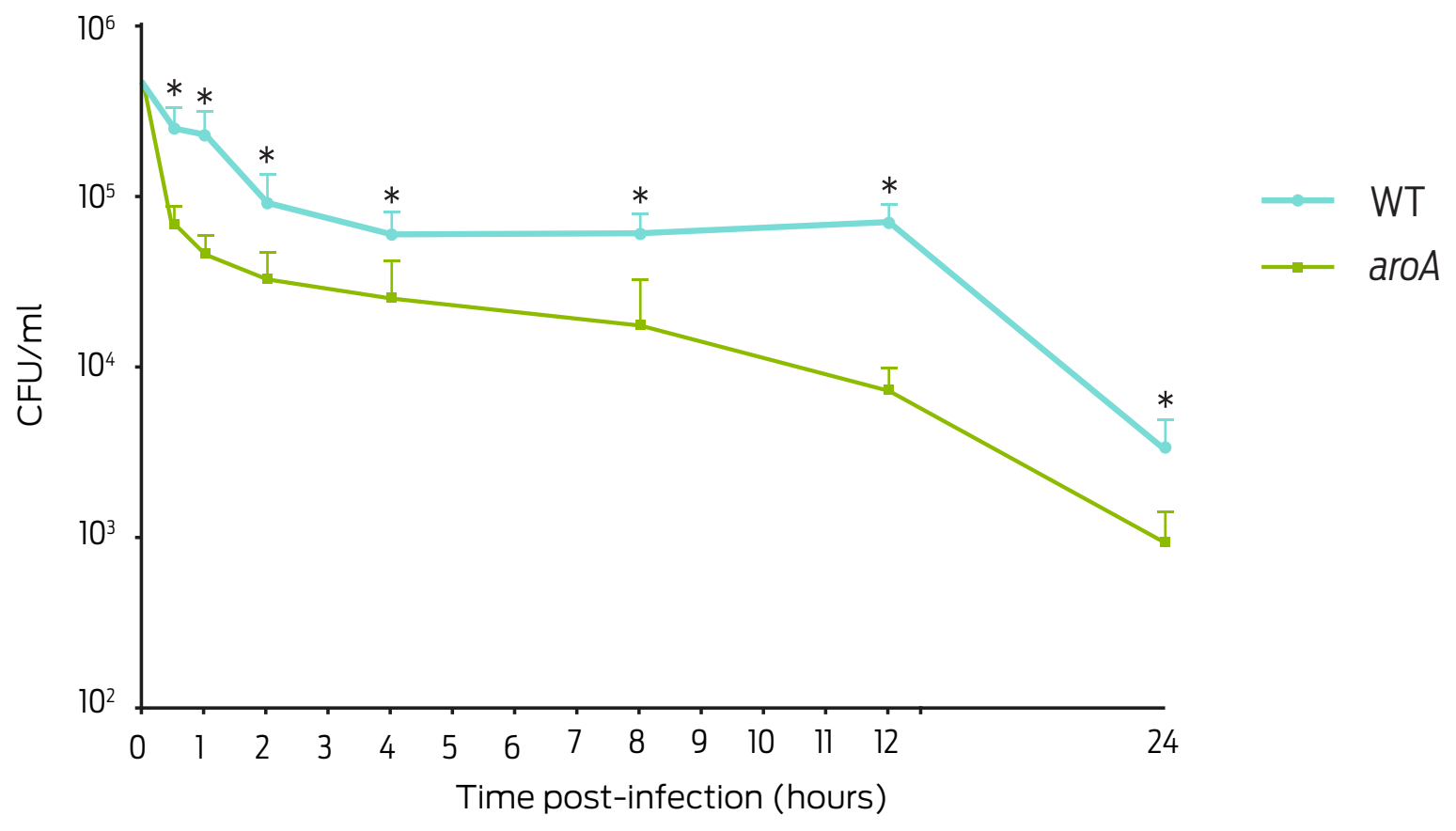

Figure 1. Intracellular survival of C. pseudotuberculosis in J774A. 1 macrophages with a Multiplicity of infection (MOI) of 1:1. The results are presented as the mean \pm standard deviation in CFU/ml after different post-infection times. Significant differences $(P<05)$ between the strains are indicated by an asterisk.

\section{Results and discussion}

\section{Evaluation in the cellular model}

The J774A.1 macrophage infections performed with the WT and aroA strains showed a significant difference 30 min post-infection as follows: $273,333.30 \pm$ 40,221.61 CFU/ml for the WT strain and 75,000.00 $\pm 8,062.26 \mathrm{CFU} / \mathrm{ml}$ for the aroA strain $(\mathrm{P}<0.05)$. For the following infection times, a gradual decrease in the number of intracellular bacteria was observed over time between the two bacteria strains: At $12 \mathrm{~h}$, one log of difference between the two strains was observed. At the end of the experiment ( $24 \mathrm{~h}$ ), the WT strain exhibited a value of 3,566 \pm 691. CFU/ml and that of the aroA mutant strain was $966.67 \pm 221.61 \mathrm{CFU} / \mathrm{ml}$ (Figure 1).

\section{Evaluation of the lesion formation at the vaccination site}

Vaccinating mice with the WT and mutant strains caused injuries on the footpad and in the subcutaneous tissue. The progression of the lesion was more rapid and severe in the mice vaccinated with the WT strain than in those vaccinated with the mutant strain. In the three WT-vaccinated mice, a well-defined nodular lesion with a diameter of approximately $1.5 \mathrm{~cm}$ was formed within the zones showing alopecia. A continuing loss of hair was compatible with the formation of an ulcer. A severe inflammatory reaction comprising macrophages and lymphocytes, which primarily affected the hypodermis with a slight invasion of the dermis, was observed microscopically. This lesion also presented a suggestive loss of cell continuity to edema. In contrast, the mice that were vaccinated with the aroA strain in their backs via subcutaneous injection exhibited a slight inflammatory reaction consisting of lymphocytes in the hypodermis region. 
At the dermis level, a suggestive loss of cell continuity to edema was observed but was less intense compared to that resulting from the WT strain. The application of the aroA mutant in the footpad caused less-severe injuries than WT strain. One mouse vaccinated via the footpad died, and others suffered liver abscesses. Microscopically, a discrete inflammatory reaction involving localized lymphocytes in the hypodermis region was observed in the aroA mutant-vaccinated mice, and at the dermis level, thus suggesting of the loss of cell continuity to edema.

In the WT-vaccinated animals, a severe inflammatory reaction comprising macrophages and lymphocytes occurred, affecting the hypodermis with a slight invasion of the dermis. A loss of cell continuity to edema was also observed in this case. In the aroA mutant-vaccinated group, an additional discrete inflammatory reaction involving mononuclear cells (lymphocytes) in the hypodermis region was observed accompanied by a loss of cell continuity to edema at the dermis level.

\section{Evaluation of the residual virulence}

Throughout the experiment, animals vaccinated with the WT strain showed $12.5 \%$ (3/24) mortality, whereas mice that were vaccinated with the aroA strain exhibited no mortality. Regarding the number of bacteria isolated from the spleen, a significant difference between the WT and aroA strains was observed on days 3; (405.55 \pm 89.58 CFU/ml vs $7.41 \pm 2.93 \mathrm{CFU} / \mathrm{ml}), 10(11,175.91 \pm 74.07 \mathrm{CFU} / \mathrm{ml}$ vs 5.50 $\pm 2.77 \mathrm{CFU} / \mathrm{ml})$, and $14(3,444.44 \mathrm{CFU} / \mathrm{ml} \pm 430.56$ vs $3.07 \pm 2.45 \mathrm{CFU} / \mathrm{ml})$. No bacteria were recovered on day 28 post-vaccination in the $\operatorname{aroA}$ mutant-vaccinated mice (Figure 2). On days 0, 3, and 6 post-vaccinations, there was no significant difference in the CFU numbers recovered from mice livers. In contrast, on day 14, the liver bacterial load of mice infected with the WT strain was significantly higher $\left(7.03 \times 10^{7} \pm 1.63 \times 10^{7} \mathrm{CFU} / \mathrm{ml}\right)$ than that of the aroA mutant-vaccinated mice (3.70 $\pm 1.69 \mathrm{CFU} / \mathrm{ml})$. On day 21 , the livers of animals infected with the WT strain had a bacterial count of 2,490.74 $\pm 305.70 \mathrm{CFU} / \mathrm{ml}$, whereas no bacteria was isolated from those infected with the aroA strain. However, on day 28 , values of $472.22 \pm 164.94 \mathrm{CFU} / \mathrm{ml}$ and $7.41 \pm 4.90 \mathrm{CFU} / \mathrm{ml}$ were determined in the livers of WT- and aroA-infected mice (Figure 2).

\section{Evaluation of the in vivo mutant protection}

To evaluate the protective ability of the aroA mutant strain against challenge, the animals were immunized and subsequently challenged with the ATCC43924 C. pseudotuberculosis strain. During the first post-challenge week, a marked significant difference $(P<05)$ was observed between the survival of the control group (41.67\%; 10/24 animals) and the aroA mutant-vaccinated group (83.33\%; $20 / 24$ animals). However, by day 28 of the experiment, survival in control group $40 \%$ was not significantly different than survival in the mutant-vaccinated mice $50 \%$ (Figure 3).

\section{Humoral immune response}

The production of $\lg \mathrm{M}, \lg \mathrm{G} 1, \lg \mathrm{g} 2 \mathrm{a}$, and $\lg \mathrm{G} 2 \mathrm{~b}$ before exposure to the aroA mutant strain was evaluated, aroA mutant-vaccinated mice showed a statistically significant 

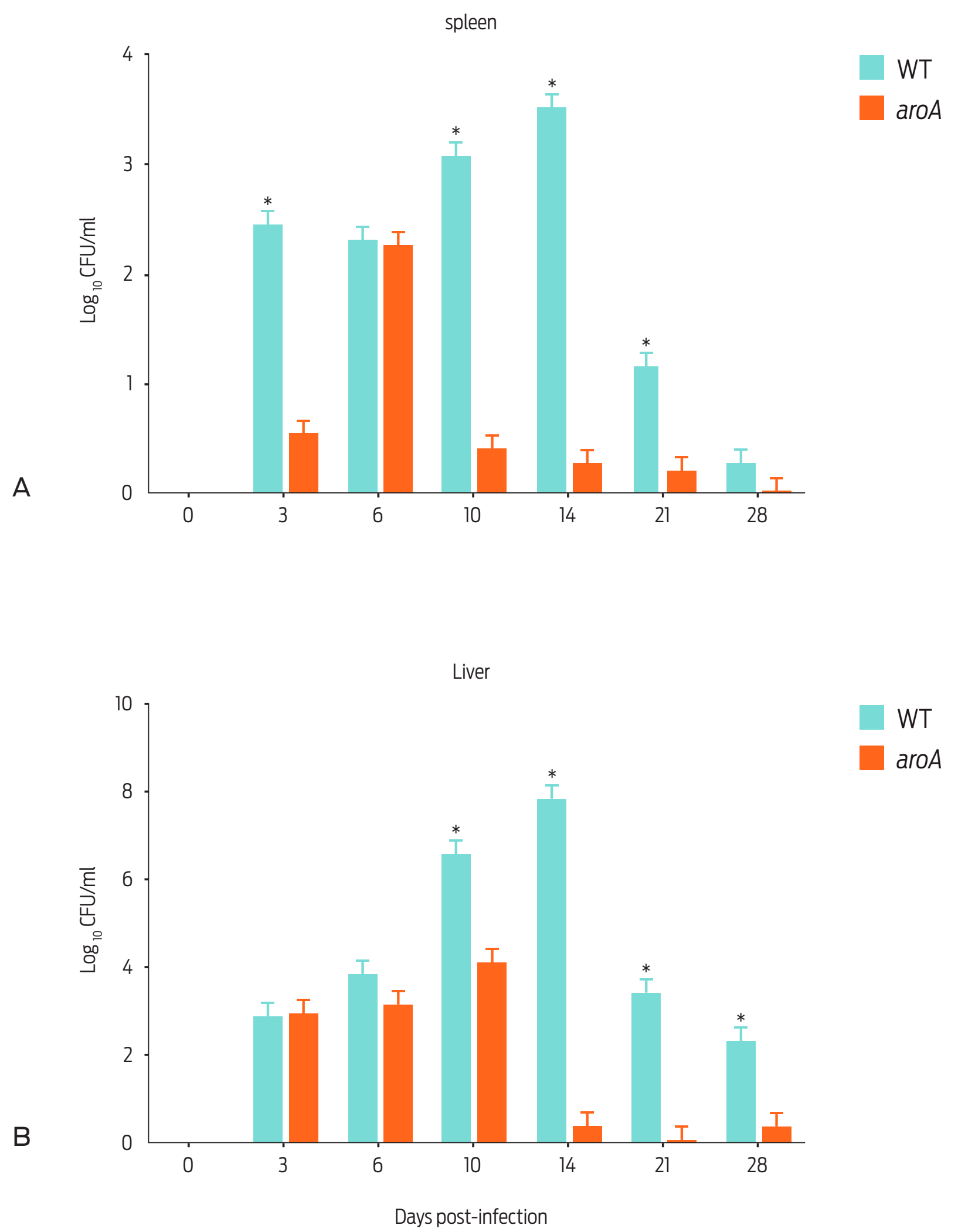

Figure 2. Recovery of the WT and aroA strains of C. pseudotuberculosis from the spleens and livers of mice that were subcutaneusly vaccinated with $2 \times 10^{6} \mathrm{CFU} / 0.1 \mathrm{ml}$. The animals were euthanized in groups of three on days $0,3,6,10$, $14,21,28,35$ and 42 post vaccination. The data represented as the mean \pm standard deviation. On days 35 and 42 , no bacteria could be recovered. Significant differences $(P<0.05)$ between mutant and parental strain are indicated by an asterisk. 


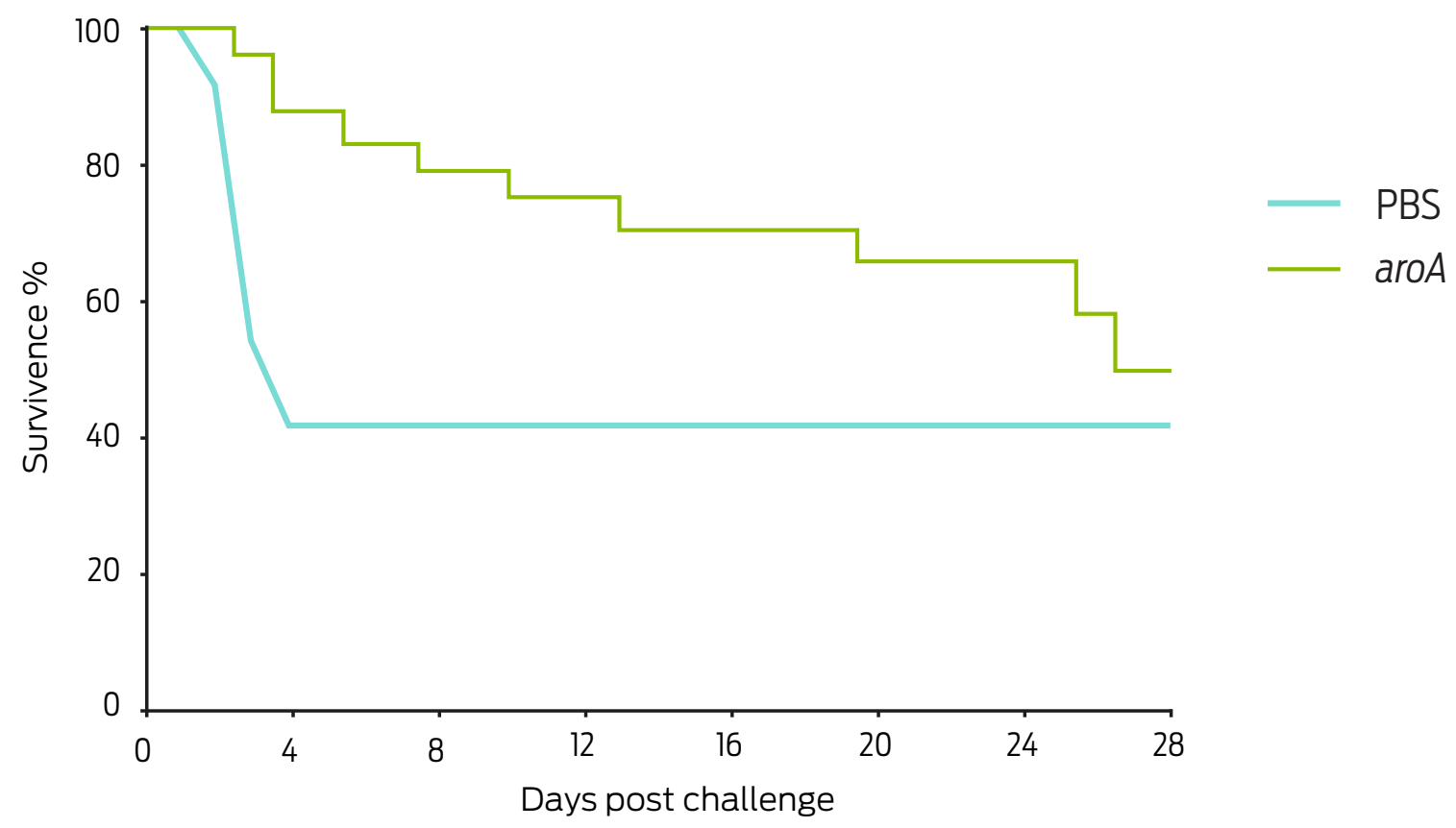

Figure 3. Survival percentage of Balb/c mice inoculated with the aroA mutant and challenged on day 21 with $1 \times 10^{4}$ CFU of the ATCC C. pseudotuberculosis strain, intraperitoneally inoculated. In the first week post-challenge, a marked survival difference between the control group (41.67\%) and the aroA mutant the vaccinated group (83.33\%) was observed ( $P<0.05$ ); however at the end of the experiment (day 28), $50 \%$ survival was observed in mutant vaccinated mice, whereas the WT-vaccinated group survival did not change.

difference relative to the control group regarding the production of the $\lg \mathrm{G} 1$ isotype between day 28 and day 42 post-vaccination $(P<0.05)$. For $\lg G 2 a$, a statistically significant difference between the control and vaccinated groups was only noted on day 28 (Figure 4). For IgM and IgG2b, no significant difference was observed.

\section{Cytokine measurement induced by vaccination}

Measuring the cytokines induced by the aroA mutant in our murine model revealed that IL-10 exhibited a significant difference between day 7 and day 12 post-vaccination (Figure 5). A study of the IFN- - , TNF-a and IL-4 responses revealed no statistically significant differences during the experiment.

This study was performed because of the need for a live vaccine to prevent caseous lymphadenitis. To date, the mutant strains that have been evaluated as possible $C$. pseudotuberculosis immunogens have failed to confer adequate protection to susceptible animals $9,21,22$. Here, the aroA mutant of $C$. pseudotuberculosis was chosen based on the good results that were obtained by applying the aro $A$ mutant of Salmonella enterica, subsp. enterica serovar Abortus equi, to guinea pigs through oral and intramuscular routes. This mutant provided the vaccinated animals with $100 \%$ protection against an experimental challenge with the virulent strain ${ }^{10}$.

The observed difference between the recovered CFU/ml values of the WT and aroA mutant strains after 30 min p.i. in J774A murine macrophages (Figure 1) can be attributed to the aroA gene mutation, which decreases the regulation of the murA gene and, in turn, increases peptidoglycan synthesis. The resulting defects in the bacterial wall causes phagocytosis and bacterial elimination ${ }^{6}$. 


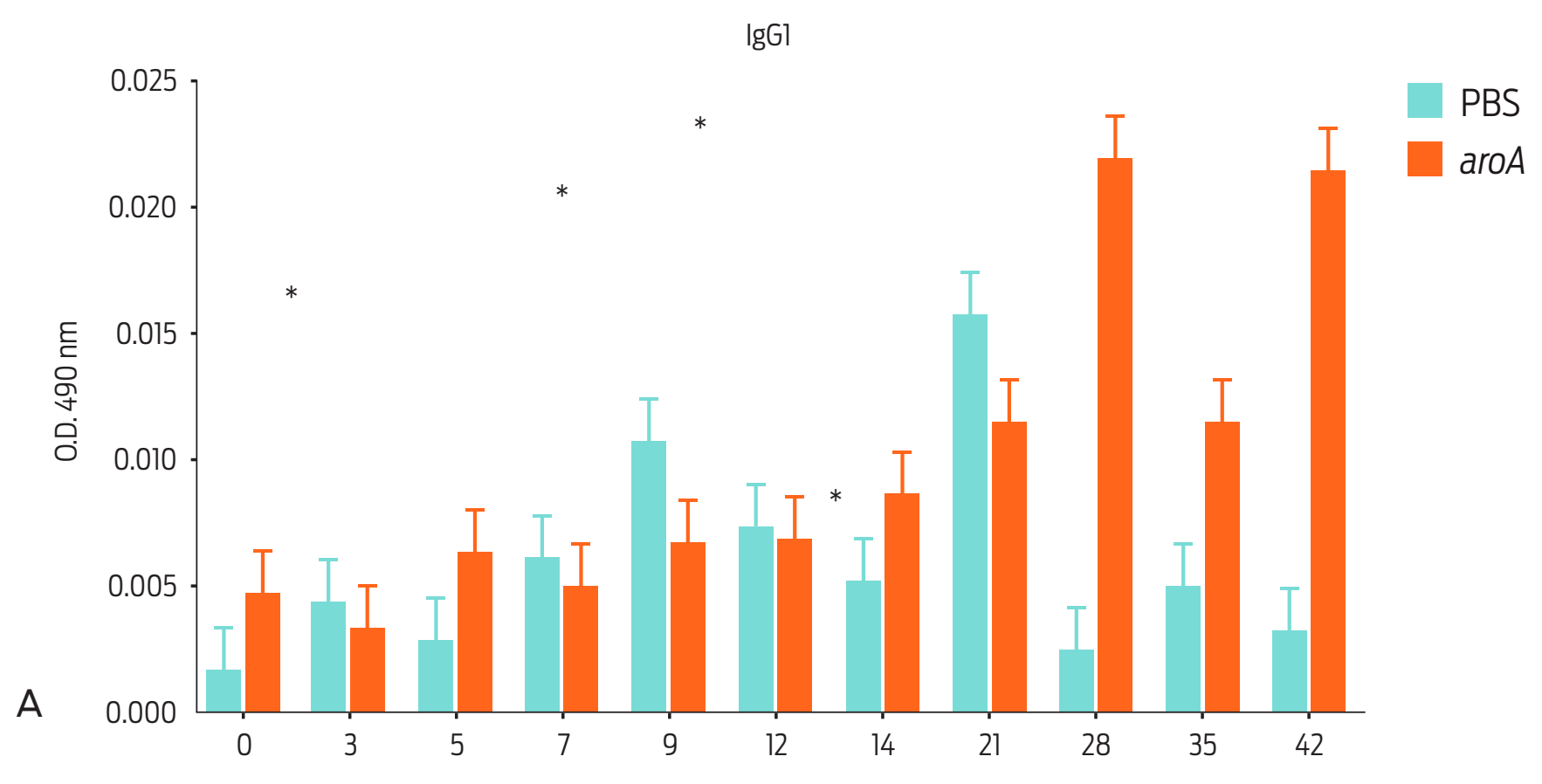

Days post-infection

$\lg G 2 a$

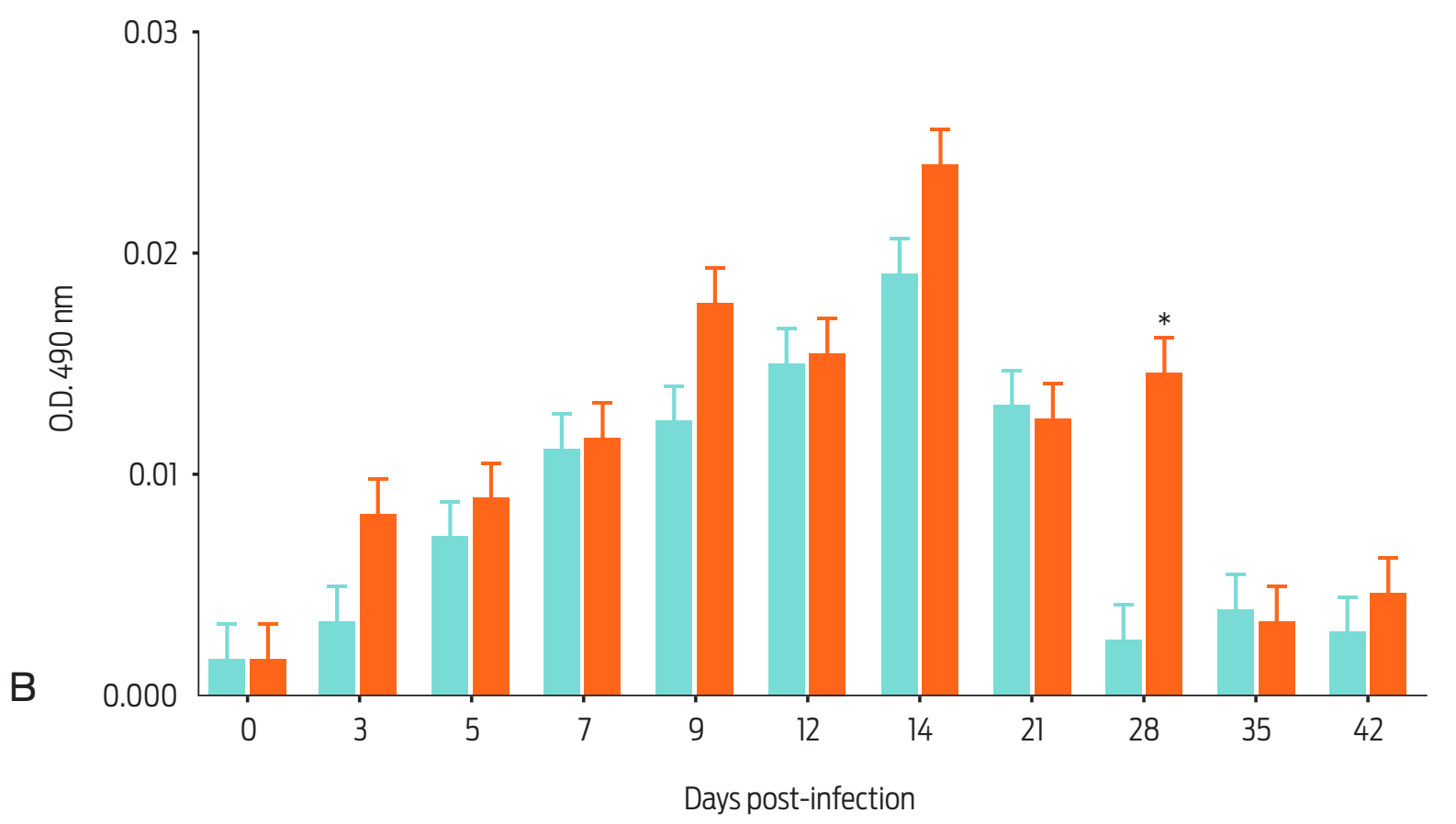

Figure 4. Humoral inmune response of mice vaccinated with the aroA mutant strain after different post vaccination times: $\lg \mathrm{G} 1$ immune response (a), and $\lg \mathrm{G} 2 \mathrm{a}$ immune response (b). Data are expressed as the mean \pm standard deviation of the sera from four mice vaccinated with aroA mutant strain and a control group injected with PBS. Statistically significant differences $(P<0.05)$ are indicated with *. 


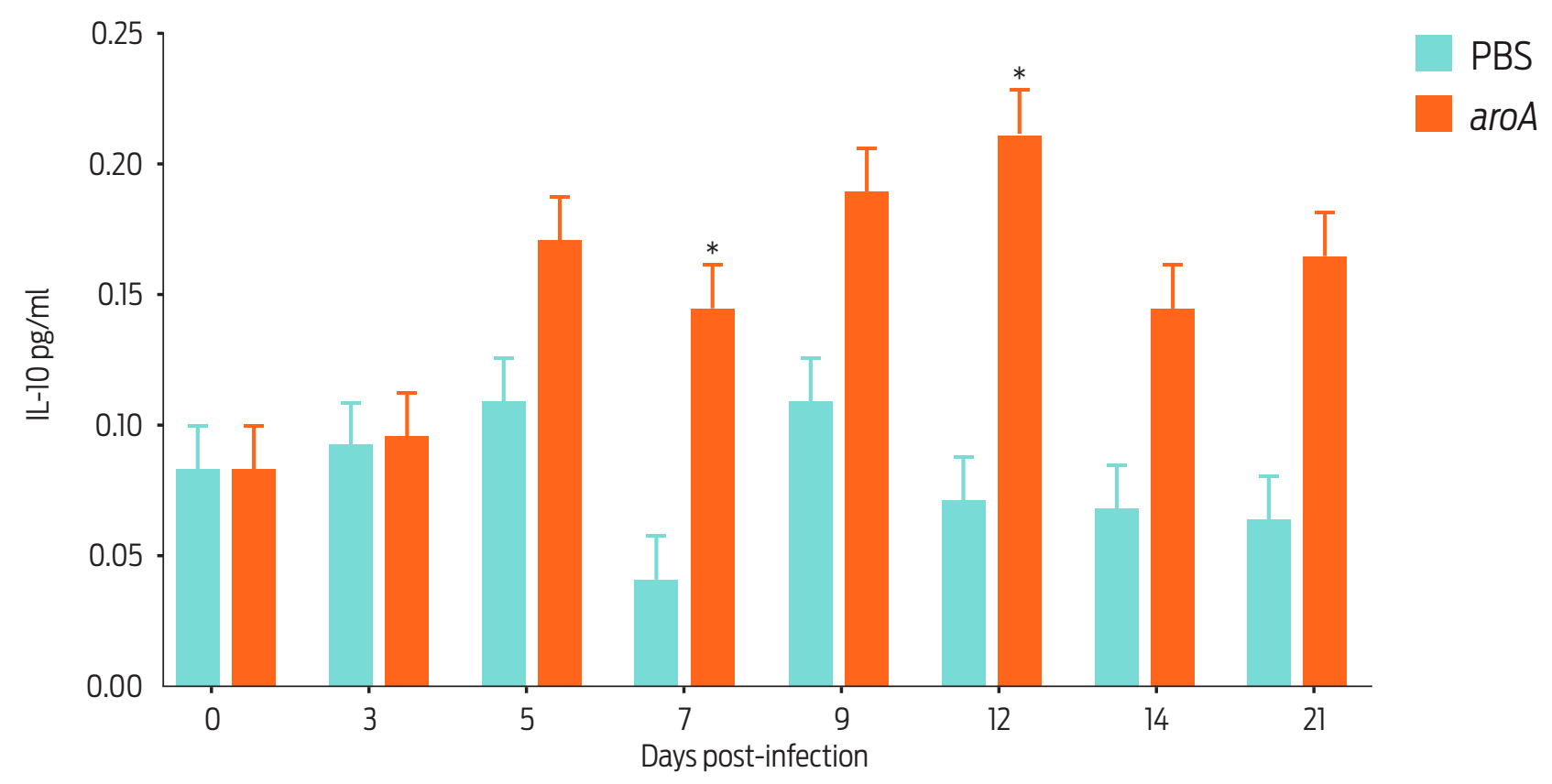

Figure 5. Cytokine detection in the culture supernatant of spleen lymphocytes from aroA mutant-vaccinated and control (PBS) BALB/c mice. The data are shown as the mean \pm standard deviation of groups of five mice on each post-vaccination day. Statistically significant differences $(P<0.05)$ are indicated with *.

One limitation on the use of immunogens to prevent caseous lymphadenitis is that they cause liquefactive necrosis at the vaccination site ${ }^{23}$. Although some degree of inflammation is desirable because it is associated with macrophage recruitment and, thus, antigen presentation, the damage should not be extensive and should not produce necrosis. We suggest that if the bacterium's virulence was reduced, it would be efficiently phagocytosed by macrophages, which would then present the antigenic components of the bacteria and facilitate the recruitment of inflammatory cells ${ }^{6}$. The application of the aroA mutant in the footpads of mice resulted in injuries that were less severe than those caused by the WT strain. Although the aroA mutant's virulence was attenuated, it still had the potential to cause abscess at the application site. Such injuries are typical of actinomycetes because these bacteria have lipids in their cell walls that induce inflammation and the modulation of dendritic cells and macrophages ${ }^{17}$. However, the phospholipase $\mathrm{D}$ action must also be considered in this context because it is the main virulence factor causing injury and damage to cell membranes. Activating this gene is undesirable because the virulence of the resulting mutants was abolished and did not stimulate the immune system ${ }^{24}$.

The reduced CFU/ml recovery in the liver and spleen of aroA mutant-vaccinated mice indicates that the host controlled this strain more effectively than the WT strain. Similar results have been reported for the aroQ mutant of C. pseudotuberculosis ${ }^{11}$ and the aroA mutants of $\mathrm{S}$. enterica ${ }^{6}$ and Listeria monocytogenes ${ }^{6}$. In these studies, it was observed that the mutant strain was recovered in lower amounts from the liver and spleen samples of BALB/C mice on days 7 and 14 post-vaccination.

Although the attenuation of the aroA mutant strain of C. pseudotuberculosis was observed relative to the WT strain in the cellular model and less injury and 
residual virulence were observed, the survival rate of the vaccinated group was only $50 \%$ by day 28 post-challenge (Figure 4). Thus, the mutant failed to confer at least $80 \%$ protection, which is desirable for an immunogen, in the vaccinated mice ${ }^{19}$. Previously, an immunogen against caseous lymphadenitis was developed by deleting the pld gene of C. pseudotuberculosis, which is related to the production of phospholipase $\mathrm{D}$, an exotoxin that is considered the major bacterial virulence factor $^{25}$. Studies in sheep immunized with a pld mutant showed $44 \%$ protection after being challenged with a WT strain ${ }^{21}$. An Hsp60 recombinant protein was used in another study, but it did not provide sufficient protection in BALB/c mice that were challenged with a $1 \times 10^{6} \mathrm{CFU}$ i. p. Actually, $100 \%$ mortality was observed on day 11 post-vaccination.

In our assay, the humoral immune response of the mutant-vaccinated group involved relatively high amounts of $\lg \mathrm{G} 1$ after day 28 post-vaccination. This type of response contributes to the Type Helper 2 ( $\mathrm{TH} 2$ ) stimulation response by activating antigen-presenting cells and cloning $B$ cells to produce neutralizing antibodies $^{26}$. The application of the aroA mutant in mice only stimulated IL-10 after day 7 post-vaccination and induced a poor cellular response as the IFN-y levels only increased on day 5 post-vaccination in the vaccinated mice. This finding was related to the poor lgG2a production associated with the Type Helper 1 ( $\mathrm{TH} 1)$ response. The behavior of this cytokine was very similar to that reported by Simmons et al. ${ }^{11}$, who immunized BALB/c mice with the aroQ mutant of C. pseudotuberculosis. The authors found that the levels of this cytokine increased significantly in the vaccinated animals only after day 7 post-vaccination and determined that the $\mathrm{TH} 1$ response was poor. The cellular immune response is known to be important for the resolution (or control) of diseases caused by intracellular bacteria, such as C. pseudotuberculosis, but its aroA mutant bacteria failed to elicit an adequate $\mathrm{TH} 1$ response. This was reflected by the aroA mutant's poor ability to adhere to and invade the murine cells, thereby reducing the bacterial antigen presentation by the main histocompatibility complex type I because these antigens were not found in adequate levels in the intracellular compartments ${ }^{9}$.

\section{Conclusions}

This study intended to attenuate Corynebacterium pseudotuberculosis virulence by affecting the process by which their cell wall is synthesized. This outcome was achieved because the aroA mutant showed lower multiplication in the cell model, and mice inoculated with the mutant showed less severe lesions than those inoculated with the wild type bacteria. However, this bacterium exhibited other virulence factors that were similar to the PLD exotoxin that must be considered when developing live vaccines.

The aro $A$ mutant of $C$. pseudotuberculosis exhibited attenuation in the cellular model and its residual virulence and successfully stimulated antibody production. Nevertheless, it failed to generate a sufficient cellular response and did not adequately protect the vaccinated BALB/c mice against the experimental challenge. In the mouse model, mutant aroA only had the capacity to protect $50 \%$ of Balb/C mice at 28 days' post- challenge, so the aro $A$ mutant of $C$. pseudotuberculosis not it is a good candidate as an immunogen. 


\section{Funding}

This research was supported by grant IN22771 1 from PAPIIT-UNAM. Cristina Ibarra Zazueta is grateful for a thesis grant from Mexico's Consejo Nacional de Ciencia y Tecnología (CONACYT).

\section{Acknowledgements}

The authors would like to thank Carlos Gustavo Vásquez-Pelaez for the statistical analysis and Pablo Vera Sánchez for his technical assistance.

\section{Conflicts of interest}

The authors declare that they have no competing interests.

\section{Author contributions}

Cristina Ibarra Zazueta: Conducted the experimental work and wrote the manuscript. Efrén Díaz Aparicio: Designed the research and wrote the manuscript.

Beatriz Arellano Reynoso, Rigoberto Hernández Castro, and Erika Gabriela Palomares Resendiz: Supervised the research and wrote the manuscript.

\section{References}

1. Songer JG, Beckenbach K, Marshall MM, Olson GB, Kelley L. Biochemical and genetic characterization of Corynebacterium pseudotuberculosis. Am J Vet Res. 1988;49(2):223-6. PMID:2831763.

2. Moraes P, Seyffert N, Silva W, Castro T, Silva R, Lima D, et al. Characterization of the Opp peptide transporter of Corynebacterium pseudotuberculosis and its role in virulence and pathogenicity. Biomed Res Int. 2014;2014:489782. doi: 10.1155/2014/489782.

3. Aleman M, Spier SJ, Wilson WD, Doherr M. Corynebacterium pseudotuberculosis infection in horses: 538 cases (1982-1993). J Am Vet Med Assoc. 1996;209(4):804-9. PMID:8756884.

4. Lopes Bastos B, Dias Portela RW, Alves Dorella F, Ribeiro D, Seyffert N, de Paula Castro TL, et al. Corynebacterium pseudotuberculosis: Immunological Responses in Animal Models and Zoonotic Potential. J Clin Cell Immunol. 2012; S4. Available from: http://dx.doi.org/10.4172/2155-9899.S4-005. doi: 10.4172/2155-9899.S4-005.

5. Moura-Costa L, Bahia R, Carminati R, Vale VL, Paule B, Portela R, et al. Evaluation of the humoral and cellular immune response to different antigens of Corynebacterium pseudotuberculosis in Caninde goats and their potential protection against caseous lymphadenitis. Vet Immunol Immunopathol. 2008;126(12):131-41. doi: 10.1016/j.vetimm.2008.06.013.

6. Sebkova A, Karasova D, Crhanova M, Budinska E, Rychlik I. aro mutations in Salmonella enterica cause defects in cell wall and outer membrane integrity. J Bacteriol. 2008;190(9):3155-60. doi:10.1128/JB.00053-08.

7. Parish $\mathrm{T}$, Stoker $\mathrm{N}$. The common aromatic amino acid biosynthesis pathway is essential in Mycobacterium tuberculosis. Microbiology. 2002;148(Pt 10):306977. doi: 10.1099/00221287-148-10-3069.

8. Trebichavsky I, Splichalova A, Rychlik I, Hojna H, Muneta Y, Mori Y, et al. Attenuated aroA Salmonella enterica serovar Typhimurium does not induce inflamma- 
tory response and early protection of gnotobiotic pigs against parental virulent LT2 strain. Vaccine. 2006;24(20):4285-9. doi: 10.1016/j.vaccine.2006.02.054.

9. Silva J, Droppa-Almeida D, Borsuk S, Azevedo V, Portela R, Miyoshi A, et al. Corynebacterium pseudotuberculosis cp09 mutant and cp40 recombinant protein partially protect mice against caseous lymphadenitis. BMC Vet Res. 2014;10:965. doi: 10.1186/s12917-014-0304-6.

10. Alam J, Singh B, Hansda D, Singh V, Verma J. Evaluation of aroA deletion mutant of Salmonella enterica subspecies enterica serovar Abortusequi for its vaccine candidate potential. Indian J Exp Biol. 2009;47(11):871-9.

11. Simmons C, Dunstan S, Tachedjian M, Krywult J, Hodgson A, Strugnell R. Vaccine potential of attenuated mutants of Corynebacterium pseudotuberculosis in sheep. Infect Immun. 1998;66(2):474-9. PMCID: PMC107930.

12. Vingataramin $L$, Frost $E$. A single protocol for extraction of gDNA from bacteria and yeast. Biotechniques. 2015;58(3):120-5. doi: 10.2144/000114263.

13. Sambrook J, Fritsch E, Maniatis T. Molecular cloning. Laboratory manual. $2^{\text {nd }}$ ed. New York, EUA: Cold Spring Harbor Laboratory Press; 1989. 1626 pp.

14. Dorella F, Estevam E, Cardoso P, Savassi B, Oliveira S, Azevedo V, et al. An improved protocol for electrotransformation of Corynebacterium pseudotuberculosis. Vet Microbiol. 2006;114(3-4):298-303. doi: 10.1016/j.vetmic.2005.12.010.

15. Stefanska I, Gierynska M, Rzewuska M, Binek M. Survival of Corynebacterium pseudotuberculosis within macrophages and induction of phagocytes death. Pol J Vet Sci. 2010;13(1):143-9.

16. Stanford K, Brogden K, McClelland L, Kozub G, Audibert F. The incidence of caseous lymphadenitis in Alberta sheep and assessment of impact by vaccination with commercial and experimental vaccines. Can J Vet Res. 1998;62(1):38-43. PMCID: PMC1 189440.

17. Treviño-Villarreal J, Vera-Cabrera L, Valero-Guillen P, Salinas-Carmona M. Nocardia brasiliensis cell wall lipids modulate macrophage and dendritic responses that favor development of experimental actinomycetoma in BALB/c mice. Infect Immun. 2012;80(10):3587-601. doi: 10.1128/IAl.00446-12.

18. Figueiredo Castro Nassar A, Miyashiro S, Gregori F, Piatti RM, Daniel GT, Gregory L. Standardization of an enzyme-linked immunosorbent assay (ELISA) for detection of antibodies anti-Corynebacterium pseudotuberculosis in sheep. Small Rumin Res. 2014;116(2-3):229-32. doi: 10.1016/j.smallrumres.2013.10.016.

19. Ribeiro D, Rocha Fde S, Leite K, Soares Sde C, Silva A, Portela R, et al. An iron-acquisition-deficient mutant of Corynebacterium pseudotuberculosis efficiently protects mice against challenge. Vet Res. 2014;45:28. doi: 10.1186/1297-9716-45-28.

20. Kaps M, Lamberson W. Bioestatistcs for animal science. An introductory text. 2nd ed: CABI International 2009. 520 p.

21. Hodgson A, Carter K, Tachedjian M, Krywult J, Corner L, McColl M, et al. Efficacy of an ovine caseous lymphadenitis vaccine formulated using a genetically inactive form of the Corynebacterium pseudotuberculosis phospholipase D. Vaccine. 1999;17(7-8):802-8. doi: 10.1016/S0264-410X(98)00264-3.

22. Rodrigues Pinho JM, Alves Dorella F, da Silva Coelho K, Toscano Fonseca C, Caldas Cardoso F, Meyer R, et al. Immunization with recombinant Corynebacterium pseudotuberculosis heat-shock protein (Hsp)-60 is able to induce an immune 


\section{Original Research}

DOl: http://dx.doi.org/10.21753/vmoa.3.4.366 Vol. 3 I No. 4 I October-December I 2016

response in mice, but fails to confer protection against infection. Open Vet Sci J. 2009;3:22-7. doi: 10.2174/1874318800903010022.

23. Baird G, Fontaine M. Corynebacterium pseudotuberculosis and its role in ovine caseous lymphadenitis. J Comp Pathol. 2007;137(4):179-210. doi: 10.1016/j. jсра.2007.07.002.

24. D'Afonseca V, Moraes P, Dorella F, Pacheco L, Meyer R, Portela R, et al. A description of genes of Corynebacterium pseudotuberculosis useful in diagnostics and vaccine applications. Gen Mol Res. 2008;7(1):252-60. PMID: 18551390.

25. McKean S, Davies J, Moore R. Expression of phospholipase D, the major virulence factor of Corynebacterium pseudotuberculosis, is regulated by multiple environmental factors and plays a role in macrophage death. Microbiology. 2007;153(Pt 7):2203-11. doi 10.1099/mic.0.2007/005926-0.

26. Dong C. Diversification of T-helper-cell lineages: finding the family root of IL-17-producing cells. Nat Rev Immunol. 2006;6(4):329-33. doi: 10.1038/nri1807. 